

\title{
Water co-catalyzed selective dehydrogenation of methanol to formaldehyde and hydrogen
}

\author{
Junjun Shan ${ }^{1 \#}$, Felicia R. Lucci ${ }^{2 \#}$, Jilei Liu ${ }^{1}$, Mostafa El-Soda ${ }^{2}$, Matthew D. \\ Marcinkowski $^{2}$, Lawrence F. Allard ${ }^{3}$, E. Charles H. Sykes ${ }^{2 *}$ and Maria Flytzani- \\ Stephanopoulos ${ }^{1 *}$ \\ ${ }^{I}$ Department of Chemical and Biological Engineering, Tufts University, Medford, MA 02155, \\ USA \\ ${ }^{2}$ Department of Chemistry, Tufts University, Medford, MA 02155, USA \\ ${ }^{3}$ Materials Science \& Technology Division, Oak Ridge National Laboratory, Oak Ridge, TN \\ 37831, USA \\ ${ }^{\#}$ These authors contributed equally to this work \\ *corresponding authors: maria.flytzani-stephanopoulos@tufts.edu; charles.sykes@tufts.edu
}

\begin{abstract}
The non oxidative dehydrogenation of methanol to formaldehyde is considered a promising method to produce formaldehyde and clean hydrogen gas. Although $\mathrm{Cu}$-based catalysts have excellent catalytic activity in the oxidative dehydrogenation of methanol, metallic $\mathrm{Cu}$ is commonly believed to be unreactive for the dehydrogenation of methanol in the absence of oxygen adatoms or oxidized copper. Herein we show that metallic $\mathrm{Cu}$ can catalyze the dehydrogenation of methanol in the absence of oxygen adatoms by using water as a co-catalyst both under realistic reaction conditions using silica-supported $\mathrm{PtCu}$ nanoparticles in a flow reactor system at temperatures below $250{ }^{\circ} \mathrm{C}$, and in ultra-high vacuum using model $\mathrm{PtCu}(111)$ catalysts. Adding small amounts of isolated $\mathrm{Pt}$ atoms into the $\mathrm{Cu}$ surface to form $\mathrm{PtCu}$ single atom alloys (SAAs) greatly enhances the dehydrogenation activity of $\mathrm{Cu}$. Under the same reaction conditions, the yields of formaldehyde from PtCu SAA nanoparticles are seven times higher than on the $\mathrm{Cu}$ nanoparticles, indicating a significant promotional effect of individual, isolated Pt atoms. Moreover, this study also shows the unexpected role of water in the activation of methanol. Water, a catalyst for methanol dehydrogenation at low temperatures, becomes a
\end{abstract}


reactant in the methanol steam reforming reactions only at higher temperatures over the same metal catalyst. 


\section{Introduction}

Formaldehyde $\left(\mathrm{CH}_{2} \mathrm{O}\right)$ is an important commodity chemical and is extensively used as the starting material for the synthesis of a large number of industrial chemicals such as ethylene glycol, dyes, drugs, and plastics [1]. It is expected that the global formaldehyde production will exceed 52 million tons per year in 2017 [2]. In industry, the majority of formaldehyde is produced by the oxidative dehydrogenation $(\mathrm{ODH})$ of methanol over iron-molybdenum mixed oxide and silver based catalysts $[3,4]$. However, in the ODH process a larger fraction of methanol is wasted in the production of by-products such as water, carbon monoxide, dimethyl ether, carbon dioxide and formic acid. Since the main by-product of non-oxidative dehydrogenation of methanol is hydrogen, it is a promising approach for obtaining formaldehyde along with hydrogen, and eliminating other by-products.

It has been reported that methanol can be dehydrogenated to formaldehyde and hydrogen without any catalyst at high temperatures $\sim 1173 \mathrm{~K}$ [5], but the yield of formaldehyde is less than $20 \%$ and the selectivity is less than $43 \%$ at the reported conditions. Therefore, an active catalyst is needed to catalyze methanol dehydrogenation more efficiently and selectively at a much lower reaction temperature. The non-oxidative dehydrogenation of methanol to formaldehyde has been extensively studied on bulk and supported transition metal oxides including $\mathrm{CuO}[6,7], \mathrm{AgO}[8$, 9], and $\mathrm{ZnO}[10,11]$. However, these catalysts have been shown to deactivate after a few hours of reaction, likely as a result of metallic particle formation on the support surface through the reduction of the metal oxide catalytic phase [3, 6-10]. In other words, the reductive environment in the methanol dehydrogenation reaction leads to fast deactivation of oxygen-containing catalysts. Once these catalysts lose their oxygen, they are not active for the non-oxidative dehydrogenation of methanol [12]. Therefore, a different metal particle preparation is in order to investigate methanol dehydrogenation in the absence of any oxygen, which is the subject of this work. 
Extensive ultra-high vacuum (UHV) studies on the interaction of methanol with various metal single crystal surfaces generally agree that either oxygen adatoms or metal oxides are required to facilitate the dehydrogenation of methanol to formaldehyde and water [13-21]. Only on a very highly stepped $\mathrm{Cu}(210)$ single crystal surface, Chen and Masel observed significant conversion of methanol to formaldehyde in the absence of oxygen [22]. To the best of our knowledge no metallic nanoparticle catalysts have been reported to effectively catalyze the dehydrogenation of methanol at low temperatures. Surprisingly, as we reported in recent UHV work, adsorbed water molecules on the $\mathrm{Cu}(111)$ surface can catalyze the dehydrogenation of methanol to formaldehyde in the absence of atomic oxygen and the reaction can be further promoted by isolated $\mathrm{Pd}$ atoms in $\mathrm{Cu}(111)$ [13]. Furthermore, we hypothesized that the low temperature desorption of $\mathrm{H}_{2}$ observed on isolated $\mathrm{Pd}$ atoms inhibits the high temperature recombinant desorption of methanol from methoxy and $\mathrm{H}$. Using scanning tunneling microscopy (STM), we observed hydrogen bonded methanol-water clusters that can assist in the dehydrogenation of methanol to form methoxy on $\mathrm{Cu}(111)$. The methoxy remains on the surface until it further dehydrogenates to formaldehyde at higher temperatures. Using Au (111) surfaces, Mullins and co-workers have demonstrated the exchange of $\mathrm{H}$ with either water or methanol and found an increased stability of $\mathrm{H}$ adatoms in the presence of water [23, 24]. This water-catalyzed dehydrogenation of methanol opens a new route for the production of formaldehyde and hydrogen in oxygen-free environments using metallic $\mathrm{Cu}$-based catalysts. These findings are also fundamentally important when considering the mechanism involved in the methanol steam reforming reaction that produces $\mathrm{CO}_{2}$, and $\mathrm{H}_{2}$, where the dehydrogenation of methanol to formaldehyde is the first elementary step [25].

$\mathrm{Pt}$ is one of the most widely used transition metal catalysts due to its superior activity for many catalytic reactions. However Pt is very expensive and scarce in nature which imposes major limitations on its practical application in catalysis. One solution is to design catalysts with single 
dispersion of Pt atoms necessary to catalyze a target reaction. Recently, development of catalysts with single-atom dispersion of a precious metal which is highly active and selective in the production of targeted products has attracted considerable attention [26-28]. Various "single- site heterogeneous catalysts" containing atomically dispersed active metal species have been reported to be high active for many catalytic reactions [29-34]. For example isolated Pt and Au cations stabilized by $-\mathrm{O}$ bonds on various supports supplying vicinal $-\mathrm{OH}$ groups have been reported as the active sites for the water-gas shift reaction [29, 30]. Atomically dispersed Au atoms in metallic Ni have been shown to dramatically suppress carbon deposition in the steam reforming of methane [33]. Single Pd and Pt atoms in metallic copper hosts catalyze selective hydrogenation reactions $[31,35]$.

In the current work we extend the UHV study of water-catalyzed methanol dehydrogenation to supported $\mathrm{PtCu}$ SAA nanoparticles; while we also explore the reactivity of $\mathrm{PtCu}(111)$ SAA model catalysts. We show here for the first time that metallic $\mathrm{Cu}$ nanoparticles can catalyze the non-oxidative dehydrogenation of methanol under realistic reaction conditions by using water as co-catalyst. The addition of small amounts of highly dispersed isolated $\mathrm{Pt}$ atoms in $\mathrm{Cu}$ greatly promotes the water-catalyzed dehydrogenation rate for model surfaces and supported nanoparticles. Additionally, we compare $\mathrm{PtCu}$ and $\mathrm{PdCu}$ SAA nanoparticles and show a more pronounced promotional effect for $\mathrm{PtCu}$ catalysts.

\section{Experimental}

$\mathrm{PtCu}$ SAA nanoparticles with various $\mathrm{Pt}$ concentrations were synthesized through the galvanic replacement (GR) method and a wet chemistry approach was followed as described in detail in our recent publications $[35,36]$. Here, we give a brief overview of the procedure. First, the metallic $\mathrm{Cu}$ nanoparticles were prepared and supported on silica. Under nitrogen protection, a 0.1 M solution of ascorbic acid was added to an aqueous solution of $\mathrm{Cu}\left(\mathrm{NO}_{3}\right)_{2}$ and PVP (200:1 
molar ratio of $\mathrm{Cu}$ to PVP). The solution of $\mathrm{NaBH}_{4}(0.1 \mathrm{M})$ was added to the Cu/PVP solution dropwise. The solution turned to an opaque brown suspension after the addition of $\mathrm{NaBH}_{4}$. Fumed silica with surface area $200 \mathrm{~m}^{2} / \mathrm{g}$ was suspended in deionized water under constant stirring and added to the $\mathrm{Cu}$ NPs colloidal solution dropwise. Afterwards, the solution was kept under nitrogen protection and constant stirring for $30 \mathrm{~min}$ before it was filtered and washed with deionized water several times. The resulting materials were dried in vacuum for $12 \mathrm{~h}$, and calcined in air to $350{ }^{\circ} \mathrm{C}$ for $4 \mathrm{~h}$. The addition of $\mathrm{Pt}$ atoms to $\mathrm{Cu}$ nanoparticles was achieved through GR, which was performed in an aqueous solution at $80{ }^{\circ} \mathrm{C}$ with nitrogen protection and constant stirring. Designed amounts of $\mathrm{H}_{2} \mathrm{PtCl}_{6} \cdot \mathrm{xH}_{2} \mathrm{O}$ (Sigma-Aldrich) were added to a suspension of $\mathrm{Cu}$ nanoparticles in an aqueous solution containing $2 \mathrm{mM} \mathrm{HCl}$. After $20 \mathrm{~min}$ reaction, the obtained material was filtered and washed with deionized water several times at $60{ }^{\circ} \mathrm{C}$, and then dried in vacuum at $60{ }^{\circ} \mathrm{C}$ for $12 \mathrm{~h}$. The Pt loading was confirmed by inductively coupled plasma (ICP) analysis.

X-ray powder diffraction (XRD) patterns were collected on a PANalytical X'Pert Pro instrument using nickel-filtered $\mathrm{Cu} \mathrm{K} \alpha$ radiation $(\lambda=1.54056 \AA)$. The measurements were taken at $45 \mathrm{kV}$ and $40 \mathrm{~mA}$ in a continuous mode. Data was collected for $2 \theta$ between $25^{\circ}$ and $80^{\circ}$. Aberration-corrected high-angle annular dark-field (HAADF) STEM images of supported PtCu SAA nanoparticles were obtained with a JEOL 2200FS-AC STEM/TEM system at Oak Ridge National Laboratory. EDS imaging was collected with a Bruker-AXS $30 \mathrm{~mm}^{2}$ silicon-drift detector system, which was operated at $200 \mathrm{kV}$ for all imaging and EDS work.

In-situ Extended X-ray absorption Fine Structure (EXAFS) measurements were performed at beamline 12-BM at Argonne National Laboratory. EXAFS data of PtCu SAAs at the $\mathrm{Pt}_{3}$-edge in fluorescence mode were collected at room temperature. All samples were reduced in $\mathrm{H}_{2}$ in situ prior to the measurements. The EXAFS data of Pt metal foil was also collected in the reference mode for X-ray energy calibration and data alignment. Approximately 10 consecutive scans were 
collected for each sample to improve the signal-to-noise ratio. EXAFS data processing and analysis were performed using the IFEFFIT package.

Methanol dehydrogenation activity on silica supported $\mathrm{Cu}$ nanoparticles and $\mathrm{PtCu}$ SAA nanoparticles was evaluated in a fixed-bed flow reactor tests at atmospheric pressure. Typically $100 \mathrm{mg}$ sample was loaded into a U-shaped quartz reactor between two layers of quartz sand and packed in between two quartz wool plugs. The catalyst was heated in a furnace equipped with a temperature controller. The temperature of the catalyst was measured with a K-type thermocouple reaching the top of the catalyst bed. Prior to testing, the catalysts were first reduced in-situ under a flow of $\mathrm{H}_{2}\left(10 \%\right.$ in argon) with a flow rate at $10 \mathrm{~mL} / \mathrm{min}$ at $300{ }^{\circ} \mathrm{C}$ for $60 \mathrm{~min}$. The typical reaction gas composition was 3\% methanol and 3\% water balanced in $\mathrm{He}$, using a flow rate of 10 $\mathrm{mL} / \mathrm{min}$ He. The effluent gas was monitored online by a residual gas analyzer (SRS RGA 200). Methanol, formaldehyde, $\mathrm{H}_{2}, \mathrm{CO}$, and $\mathrm{CO}_{2}$ were monitored by $\mathrm{m} / \mathrm{z}=31,30,2,28$, and 44 respectively. In addition, in the case of formaldehyde, the contribution from the methanol fragment was subtracted from the original $\mathrm{m} / \mathrm{z}=30$ signal prior to further processing.

$\mathrm{PtCu}$ SAA model catalysts were probed using temperature programmed desorption/reaction (TPD/R) and scanning tunneling microscopy (STM) experiments in multiple UHV chambers with base pressures $<1 \times 10^{-10}$ mbar. $\mathrm{Cu}(111)$ single crystals were cleaned with cycles of $\mathrm{Ar}^{+}$sputtering $(1.5 \mathrm{keV}, 15 \mu \mathrm{A})$ and annealing to $700 \mathrm{~K}$. The roughened $\mathrm{Cu}(111)$ surface was prepared without the final anneal to $700 \mathrm{~K}$. Pt was deposited using a flux monitored EFM 3 electron beam evaporator (Focus GmbH). Pt was deposited at a flux of 0.02 monolayer (ML) $\min ^{-1}$ while holding the $\mathrm{Cu}(111)$ sample at $380 \mathrm{~K}$. STM images of $\mathrm{Cu}(111)$ and $\mathrm{PtCu}(111)$ SAA were acquired using a variable-temperature STM (VT-STM) (Omicron NanoTechnology) at room temperature. A low-temperature STM (LT-STM) (Omicron NanoTechnology) was used to image the roughened $\mathrm{Cu}$ surface at $5 \mathrm{~K}$ due to the high mobility of $\mathrm{Cu}$ atoms at step edges. 
TPD/R experiments were performed in another chamber where the model catalysts were cooled to $85 \mathrm{~K}$ with liquid nitrogen before reactants were deposited. A linear heat ramp of $1 \mathrm{Ks}^{-1}$ was applied and desorbing species were detected with a quadruple mass spectrometer. Methanol (Alfa Aesar, ultrapure HPLC grade 99.8\%), water (deionized $\mathrm{H}_{2} \mathrm{O}$ ), and methanol-D (SigmaAldrich, 99.5\%) were further purified via freeze-pump-thaw cycles prior to deposition via a high precision leak valve. All exposures are quoted in Langmuirs $\left(1 \mathrm{~L}=1 * 10^{-6}\right.$ torr $\left.\times 1 \mathrm{sec}\right)$. Pt surface coverages and $\mathrm{Cu}$ step densities were quantified by $\mathrm{CO}$ (99.99\% Airgas) titration after saturating the surface with $\mathrm{CO}(10 \mathrm{~L})$. CO desorption from $\mathrm{Cu}$ terraces occurred at $<200 \mathrm{~K}, \mathrm{Cu}$ step sites at $205 \mathrm{~K}$, and Pt sites at $>300 \mathrm{~K}$.

\section{Results and discussion}

Inspired by the interesting finding of water-catalyzed methanol dehydrogenation on $\mathrm{Cu}(111)$ and $\mathrm{Pd} / \mathrm{Cu}(111)$ SAA model catalysts [13], we prepared silica supported $\mathrm{Cu}$ nanoparticles and $\mathrm{PtCu}$ SAA nanoparticle catalysts and examined their catalytic performance for methanol dehydrogenation in the presence of water under realistic reaction conditions. As discussed below, the atomic distribution of Pt atoms on the $\mathrm{Cu}$ surface was confirmed by STEM, EDS, and EXAFS analysis. 


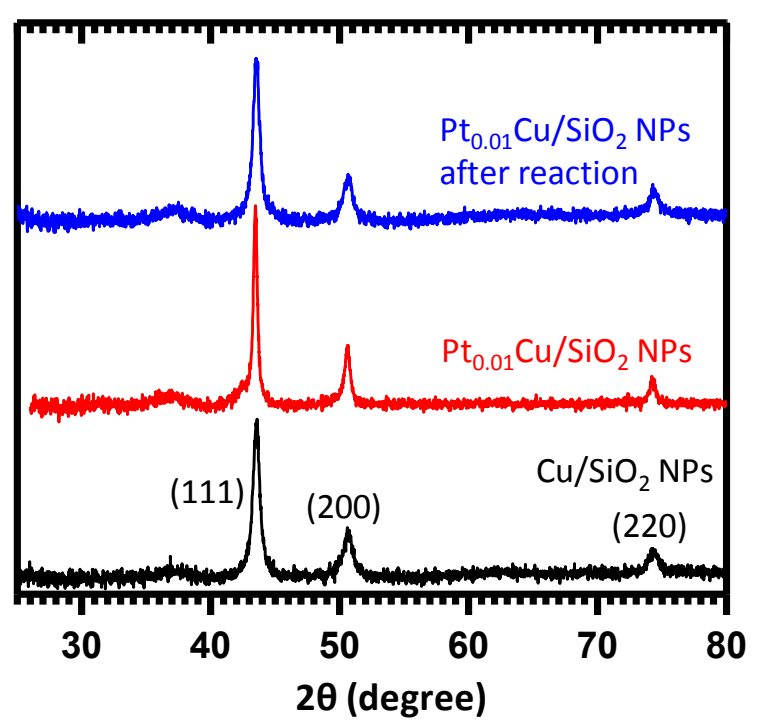

Fig.1 XRD patterns of as-synthesized silica supported $\mathrm{Cu}$ nanoparticles and $\mathrm{Pt}_{0.01} \mathrm{Cu}$ SAA nanoparticles before and after the water-catalyzed methanol dehydrogenation reaction.

Fig. 1 shows the XRD patterns of as-synthesized silica supported $\mathrm{Cu}$ nanoparticles (bottom trace), as-synthesized silica supported $\mathrm{Pt}_{0.01} \mathrm{Cu}$ SAA nanoparticles (middle trace), and silica supported $\mathrm{Pt}_{0.01} \mathrm{Cu}$ SAA nanoparticles after the water-catalyzed methanol dehydrogenation reaction (top trace). The XRD pattern of the supported $\mathrm{Cu}$ nanoparticles shows metallic $\mathrm{Cu}$ diffraction peaks, (111), (200) and (220) [37]. A rather broad peak centered at $37^{\circ}$ is also present, which is attributed to the (111) diffraction of $\mathrm{Cu}_{2} \mathrm{O}$ [37]. The appearance of a small $\mathrm{Cu}_{2} \mathrm{O}$ peak is expected since the $\mathrm{Cu}_{2} \mathrm{O}$ phases are thermodynamically more stable than metallic $\mathrm{Cu}$ nanoparticles $[37,38]$. Prior to reactivity testing, the oxide was removed via reduction in a $\mathrm{H}_{2}$ atmosphere. XRD patterns of as-synthesized silica-supported $\mathrm{Pt}_{0.01} \mathrm{Cu}$ SAA nanoparticles show no observable difference as compared to $\mathrm{Cu}$ nanoparticles, indicating that introduction of small amounts of Pt through GR does not change the lattice structure of the $\mathrm{Cu}$ nanoparticles. Moreover, the XRD pattern of supported $\mathrm{Pt}_{0.01} \mathrm{Cu}$ SAA nanoparticles after the reaction is preserved, suggesting that the water-catalyzed methanol dehydrogenation reaction does not alter the lattice 
structure of $\mathrm{Cu}$. In all three cases, the average crystallite size of $\mathrm{Cu}$ was estimated to be $\sim 14 \mathrm{~nm}$ as determined by the Scherrer equation.

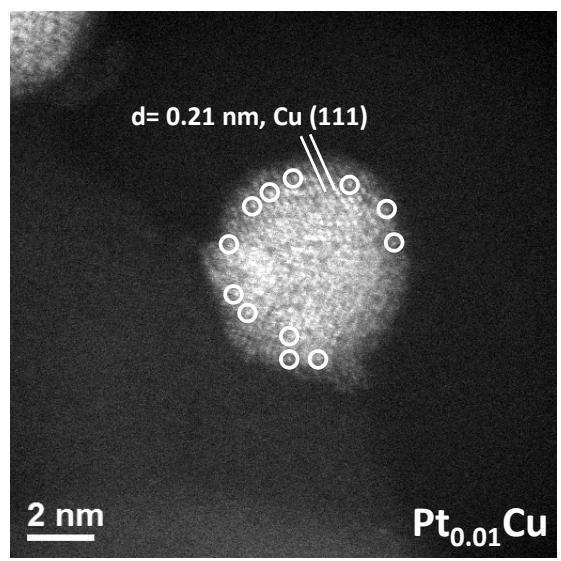

Fig. 2 ac-HAADF-STEM image of a typical region of the $\mathrm{Pt}_{0.01} \mathrm{Cu} / \mathrm{SiO}_{2}$ sample. The sample was prereduced in $\mathrm{H}_{2}$ at $350{ }^{\circ} \mathrm{C}$. Some of the isolated Pt atoms are highlighted by white circles.

An ac-HAADF-STEM image of the silica-supported $\mathrm{Pt}_{0.01} \mathrm{Cu}$ SAA nanoparticles is shown in Fig. 2. The sample was pre-reduced in $\mathrm{H}_{2}$ atmosphere at $350{ }^{\circ} \mathrm{C}$. The isolated $\mathrm{Pt}$ atoms are brighter than the $\mathrm{Cu}$ areas in the dark field STEM image. Thus, we can identify the isolated Pt atoms from their higher brightness compared to their surrounding area. The white circles highlight some of the isolated Pt atoms. Therefore the STEM imaging supports the formation of isolated $\mathrm{Pt}$ atoms in $\mathrm{Cu}$. In addition, Fig. 3 shows the elemental mapping by energy dispersive $\mathrm{X}$ ray spectroscopy (EDS) of the silica-supported $\mathrm{Pt}_{0.01} \mathrm{Cu}$ SAA nanoparticles and the silica support. The EDS sample was mounted on a carbon-film-coated Be grid. EDS clearly shows that Pt was only distributed on the $\mathrm{Cu}$ nanoparticles and not on the silica support by comparing the elemental maps of $\mathrm{Pt}$ and $\mathrm{Cu}$. 


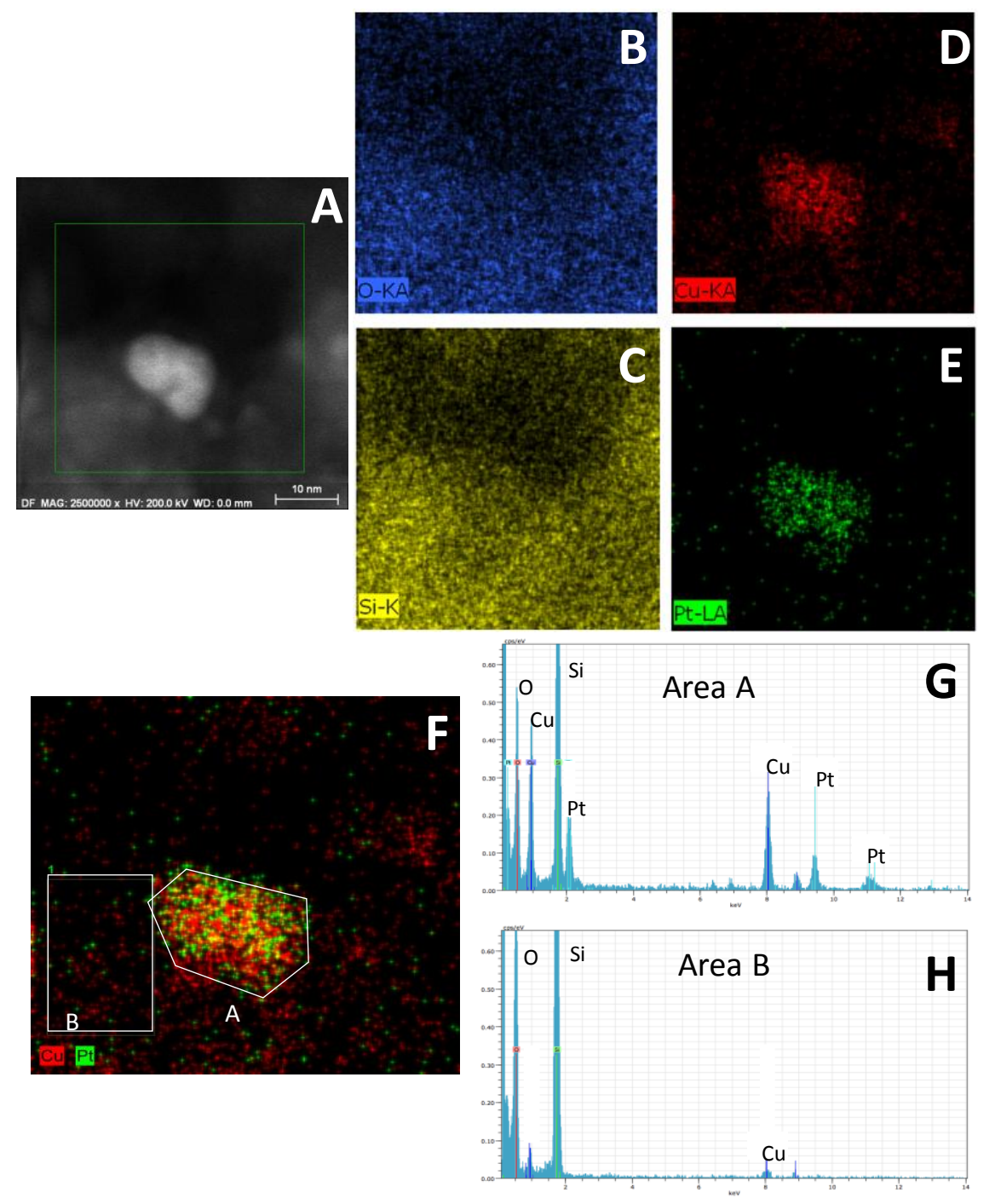

Fig. 3 (A) Bright-field STEM image of $\mathrm{Pt}_{0.01} \mathrm{Cu} / \mathrm{SiO}_{2}$ SAA nanoparticles. (B) O, (C) $\mathrm{Si}$, (D) $\mathrm{Cu}$ and (E) Pt elemental maps obtained from the same region on the sample. (F) EDS of the sample. (G) EDS spectra obtained from a $\mathrm{Cu}$ nanoparticle (region A), and (H) EDS spectra obtained from the silica support (region B). The EDS sample was mounted on a carbon-film-coated Be grid. 


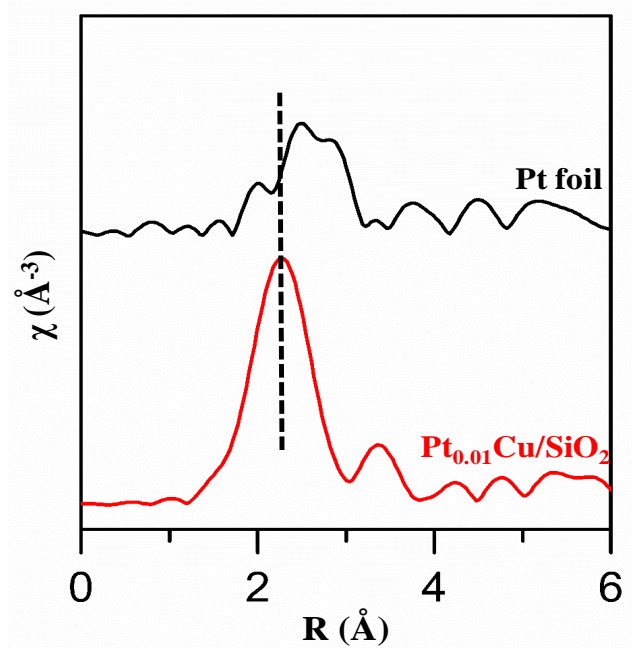

Fig. $4 \mathrm{Pt} \mathrm{L}_{3}$-edge EXAFS data of as-synthesized silica supported $\mathrm{Pt}_{0.01} \mathrm{Cu}$ SAA nanoparticles. The sample was pre-reduced in-situ with $\mathrm{H}_{2}$ at $300^{\circ} \mathrm{C}$ prior to collecting the data at room temperature.

Table 1. Quantitative analyses for Pt-Pt and PtCu contributions to the EXAFS data.

\begin{tabular}{|c|c|c|c|c|}
\hline Samples & Shell & $\mathrm{CN}^{[\mathrm{a}]}$ & $\mathrm{R}(\mathrm{A})^{[\mathrm{b}]}$ & $\sigma^{2}\left(\mathrm{~A}^{2}\right)$ \\
\hline $\mathrm{Pt}$ foil & $\mathrm{Pt}-\mathrm{Pt}$ & 12 & 2.77 & 0.0054 \\
\hline \multirow{2}{*}{$\mathrm{PtCu} / \mathrm{SiO}_{2}$} & $\mathrm{Pt}-\mathrm{Pt}$ & 0 & & \\
\cline { 2 - 5 } & $\mathrm{PtCu}$ & $10.6 \pm 4.1$ & $2.59 \pm 0.01$ & 0.0042 \\
\hline
\end{tabular}

[a] CN, coordination number; [b] R, distance between absorber and backscattered atoms.

EXAFS data of the silica supported $\mathrm{Pt}_{0.01} \mathrm{Cu}$ SAA nanoparticles are shown in Fig. 4. The sample was pre-reduced in-situ with $\mathrm{H}_{2}$ at $300{ }^{\circ} \mathrm{C}$ for $1 \mathrm{~h}$ and cooled down to room temperature in a $\mathrm{H}_{2}$ atmosphere prior to collecting the EXAFS data at the $\mathrm{Pt}_{\mathrm{L}_{3}}$-edge in fluorescence mode at room temperature in a $\mathrm{H}_{2}$ atmosphere. Further quantitative analysis revealed that there is no $\mathrm{Pt}-\mathrm{Pt}$ bonding in the silica supported $\mathrm{Pt}_{0.01} \mathrm{Cu}$ SAA nanoparticles, as shown in Table 1 . The EXAFS data therefore clearly confirms the atomic distribution of $\mathrm{Pt}$ atoms in the $\mathrm{Cu}$ surface agreeing with the STEM characterization of the silica supported PtCu SAA nanoparticles. On the other hand, 
the $\mathrm{Pt}-\mathrm{Cu}$ coordination number $(\mathrm{CN})$ is 10.6 for $\mathrm{Pt}_{0.01} \mathrm{Cu} / \mathrm{SiO}_{2}$, which is between the $\mathrm{CN}$ of the bulk (12) and surface (9), inferring that Pt atoms reside in both the surface and bulk. Though galvanic replacement method exchanges surface atoms, the samples have been pre-reduced in-situ at $300^{\circ} \mathrm{C}$ prior to the EXAFS measurements. At this temperature the $\mathrm{Pt}$ and $\mathrm{Cu}$ atoms may have significant mobility to diffuse into the bulk of the nanoparticles. Due to the error in $\mathrm{CN}$ measurements, we cannot conclude the absolute distribution of Pt in $\mathrm{Cu}$ host based on the EXAFS characterization.

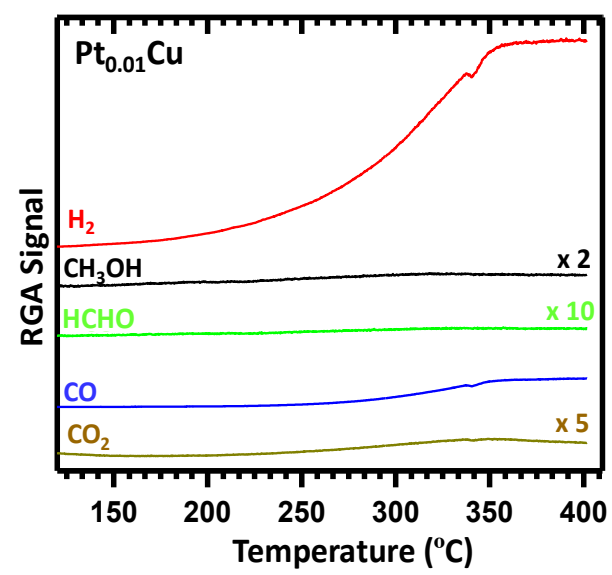

Fig. 5 TPSR of methanol on silica supported $\mathrm{Pt}_{0.01} \mathrm{Cu}$ SAA nanoparticles. Reaction conditions: $100 \mathrm{mg}$ catalyst, $13 \%$ methanol balanced in $\mathrm{He}$, He flow rate $10 \mathrm{~mL} / \mathrm{min}$. During the reaction, the gas concentration of $\mathrm{H}_{2}$ increased from $0.7 \%$ to $12 \%$, and the concentration of $\mathrm{CO}$ increased from $1 \%$ to $7 \%$.

We first examined the dehydrogenation of methanol in the absence of water on the silicasupported $\mathrm{Cu}$ nanoparticles and $\mathrm{Pt}_{0.01} \mathrm{Cu}$ SAA nanoparticles. Fig. 5 shows the temperatureprogrammed surface reaction (TPSR) of methanol on silica supported $\mathrm{Pt}_{0.01} \mathrm{Cu}$ SAA nanoparticles in the absence of water. No formation of formaldehyde was observed up to $400{ }^{\circ} \mathrm{C}$. Above $350{ }^{\circ} \mathrm{C}$, the full decomposition of methanol to $\mathrm{H}_{2}$ and $\mathrm{CO}$ was observed. The change of the $\mathrm{H}_{2}$ and $\mathrm{CO}$ concentrations follows the $2: 1 \mathrm{H}_{2}$ to $\mathrm{CO}$ stoichiometric ratio in the methanol decomposition reaction. Similar TPSR data of methanol on silica-supported $\mathrm{Cu}$ nanoparticles were obtained (not shown here). Therefore the TPSR of methanol indicates that both PtCu SAA nanoparticles and 
$\mathrm{Cu}$ nanoparticles are not active in the dehydrogenation of methanol to formaldehyde in the absence of water.

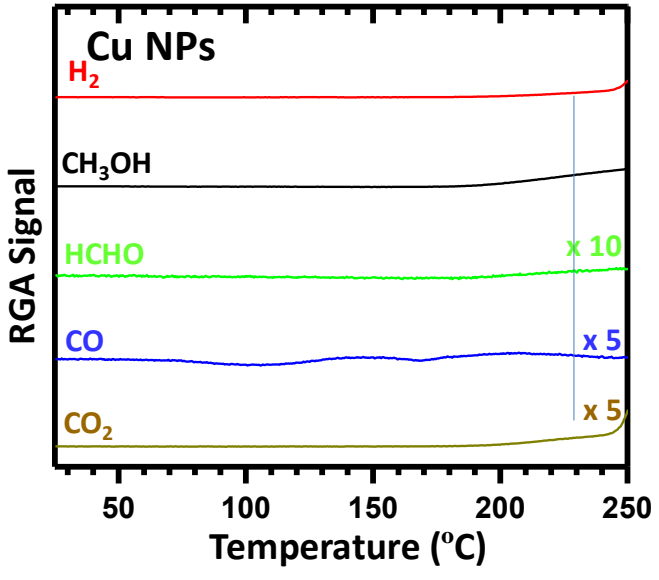

(A)

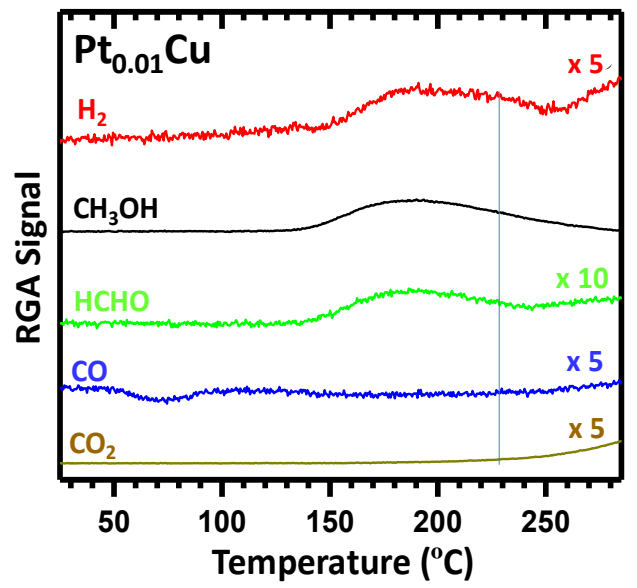

(B)

Fig. 6 TPSR of methanol in the presence of water (water:methanol $=1: 1)$ on silica supported $\mathrm{Cu}$ nanoparticles (A) and on silica supported $\mathrm{Pt}_{0.01} \mathrm{Cu}$ SAA nanoparticles (B). Reaction conditions: 100mg catalyst, $3 \%$ methanol and $3 \%$ water balanced in $\mathrm{He}$, He flow rate $10 \mathrm{~mL} / \mathrm{min}$.

Fig. 6 shows the TPSR of methanol on silica supported $\mathrm{Cu}$ nanoparticles (A) and on silica supported $\mathrm{Pt}_{0.01} \mathrm{Cu} \mathrm{SAA}$ nanoparticles (B) in the presence of water. In both cases, the water to methanol ratio was kept at 1:1. Clearly, formaldehyde is formed in both cases. The contribution of formaldehyde from the methanol fragment in the mass spectrometer was subtracted from the original $\mathrm{m} / \mathrm{z}=30$ signal prior to the product analysis. At $230{ }^{\circ} \mathrm{C}$ the yield of formaldehyde on $\mathrm{Cu}$ nanoparticles is $\sim 0.5 \%$; while the yield of formaldehyde on $\mathrm{Pt}_{0.01} \mathrm{Cu}$ SAA nanoparticles at is $\sim 7 \%$. At lower Pt loadings, a lower yield of formaldehyde (3\%) was observed for $\mathrm{Pt}_{0.003} \mathrm{Cu}$ SAA nanoparticles indicating that as expected, a higher concentration of single $\mathrm{Pt}$ atoms in $\mathrm{Cu}$ increases the conversion (Table 2). The formation of $\mathrm{CO}$ and $\mathrm{CO}_{2}$ at $230{ }^{\circ} \mathrm{C}$ is negligible; hence the selectivity to formaldehyde at $230{ }^{\circ} \mathrm{C}$ on supported $\mathrm{Pt}_{0.01} \mathrm{Cu}$ SAA nanoparticles approaches $100 \%$. Higher $\mathrm{Pt}$ concentrations such as nanoparticles of $\mathrm{Pt}_{0.1} \mathrm{Cu}$, catalyzed the full decomposition of methanol to $\mathrm{CO}$ and $\mathrm{H}_{2}$ under the same reaction conditions (not shown here). This result is 
consistent with the formation of Pt clusters or nanoparticles, which are very active for the decomposition of methanol [39].

Table 2. The yield of formaldehyde at $230{ }^{\circ} \mathrm{C}$ from various catalysts operating at different water to methanol ratios

\begin{tabular}{|c|c|c|c|}
\hline Sample & $\begin{array}{c}\text { Water to } \\
\text { methanol ratio }\end{array}$ & Reaction conditions & $\begin{array}{c}\text { Formaldehyde } \\
\text { yield }\end{array}$ \\
\hline $\mathrm{Cu} / \mathrm{SiO}_{2}$ & $1: 1$ & $\begin{array}{c}\text { 100mg catalyst, 3\% methanol, } \\
3 \% \text { water, } 10 \mathrm{~mL} / \mathrm{min}\end{array}$ & $0.5 \%$ \\
\hline $\mathrm{Pt}_{0.003} \mathrm{Cu} / \mathrm{SiO}_{2}$ & $1: 1$ & $\begin{array}{c}\text { 100mg catalyst, 3\% methanol, } \\
3 \% \text { water, } 10 \mathrm{~mL} / \mathrm{min}\end{array}$ & $3 \%$ \\
\hline $\mathrm{Pt}_{0.01} \mathrm{Cu} / \mathrm{SiO}_{2}$ & $1: 1$ & $\begin{array}{c}100 \mathrm{mg} \text { catalyst, } 3 \% \text { methanol, } \\
3 \% \text { water, } 10 \mathrm{~mL} / \mathrm{min}\end{array}$ & $7 \%$ \\
\hline $\mathrm{Pt}_{0.01} \mathrm{Cu} / \mathrm{SiO}_{2}$ & $1: 5$ & $\begin{array}{c}\text { 100mg catalyst, } 9 \% \text { methanol, } \\
2 \% \text { water, } 10 \mathrm{~mL} / \text { min }\end{array}$ & 0 \\
\hline $\mathrm{Pt}_{0.01} \mathrm{Cu} / \mathrm{SiO}_{2}$ & $3: 1$ & $\begin{array}{c}100 \mathrm{mg} \text { catalyst, } 3 \% \text { methanol, } \\
9 \% \text { water, } 10 \mathrm{~mL} / \mathrm{min}\end{array}$ & $1.2 \%$ \\
\hline $\mathrm{Pt}_{0.01} \mathrm{Cu} / \mathrm{SiO}_{2}$ & $7: 1$ & $\begin{array}{c}100 \mathrm{mg} \text { catalyst, } 1 \% \text { methanol, } \\
7 \% \text { water, } 10 \mathrm{~mL} / \mathrm{min}\end{array}$ & $7 \%$ \\
\hline $\mathrm{Pd}_{0.01} \mathrm{Cu} / \mathrm{SiO}_{2}$ & $1: 1$ & $\begin{array}{c}100 \mathrm{mg} \text { catalyst,3\% methanol, } \\
3 \% \text { water, } 10 \mathrm{~mL} / \mathrm{min}\end{array}$ & $0.8 \%$ \\
\hline
\end{tabular}

Interestingly, desorption of methanol at higher temperatures was seen in the presence of water but not observed in the absence of water (Fig. 5 and 6). The detection of methanol at $150^{\circ}$ $\mathrm{C}$ in the presence of water could be due to an increase in methoxy formation facilitated by the methanol-water complex that we previously observed with STM for $\mathrm{PdCu}(111)$ [13]. Potentially, at higher temperatures, the increased coverage of methoxy species on the surface could undergo recombination with $\mathrm{H}$ atoms to desorb as methanol or further dehydrogenate to formaldehyde. At higher temperatures $\left(>250{ }^{\circ} \mathrm{C}\right)$, the selectivity to formaldehyde decreases due to light off of the methanol steam reforming reaction. 


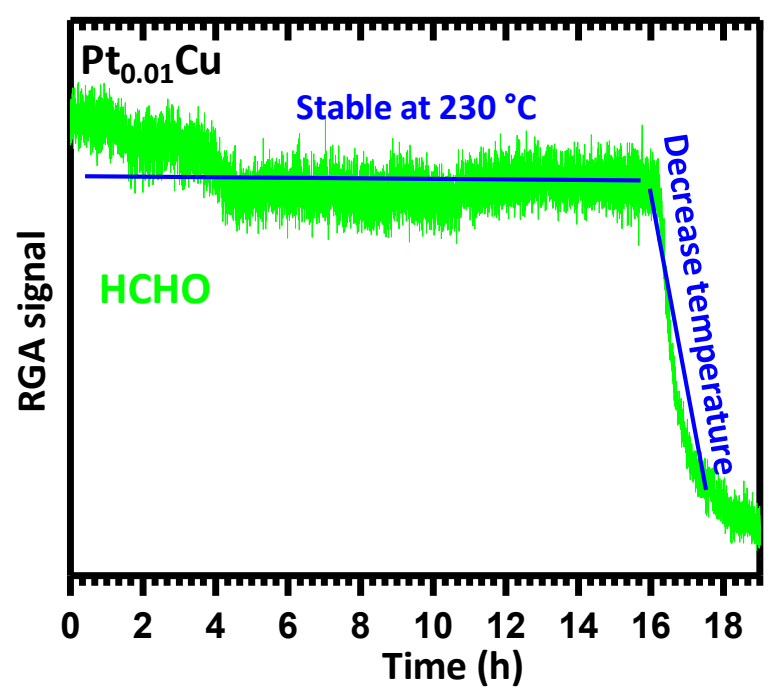

Fig. 7 Stability test of the silica supported $\mathrm{Pt}_{0.01} \mathrm{Cu}$ SAA nanoparticles in the water-catalyzed methanol dehydrogenation at $230{ }^{\circ} \mathrm{C}$ (water:methanol $\left.=1: 1\right)$.

Fig. 7 shows the stability of the silica-supported $\mathrm{Pt}_{0.01} \mathrm{Cu}$ SAA nanoparticle catalyst in the water-catalyzed methanol dehydrogenation reaction at $230{ }^{\circ} \mathrm{C}$. The water to methanol ratio was kept at $1: 1$. The yield of formaldehyde was rather constant at $230{ }^{\circ} \mathrm{C}$ up to $16 \mathrm{~h}$, indicating good stability of the silica supported $\mathrm{Pt}_{0.01} \mathrm{Cu}$ SAA nanoparticle catalyst in the reaction. The good stability of PtCu SAAs was also confirmed by UHV studies, as will be discussed below.

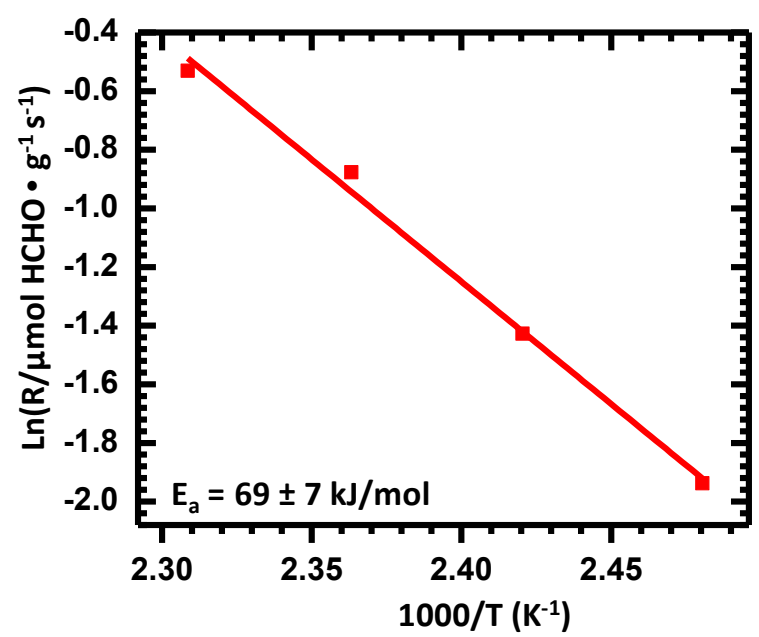

Fig. 8 Arrhenius-type plot of the reaction rate over the silica supported $\mathrm{Pt}_{0.01} \mathrm{Cu}$ SAA nanoparticles for the water co-catalyzed methanol dehydrogenation reaction. 
Kinetic studies of the water catalyzed methanol dehydrogenation on PtCu SAA nanoparticles were performed by measuring the conversion of methanol at different temperatures under steadystate conditions. Fig. 8 shows an Arrhenius-type plot of the reaction rate on the silica-supported $\mathrm{Pt}_{0.01} \mathrm{Cu} \mathrm{SAA}$ nanoparticles. The water to methanol ratio was kept at 1:1 during the whole measurement. To ensure the apparent activation energy $\left(\mathrm{E}_{\mathrm{a}}\right)$ was obtained in the kinetically controlled regime, the conversions of methanol were kept below 10\%. The apparent activation energy calculated from the Arrhenius plot is $69 \pm 7 \mathrm{~kJ} / \mathrm{mol}$.

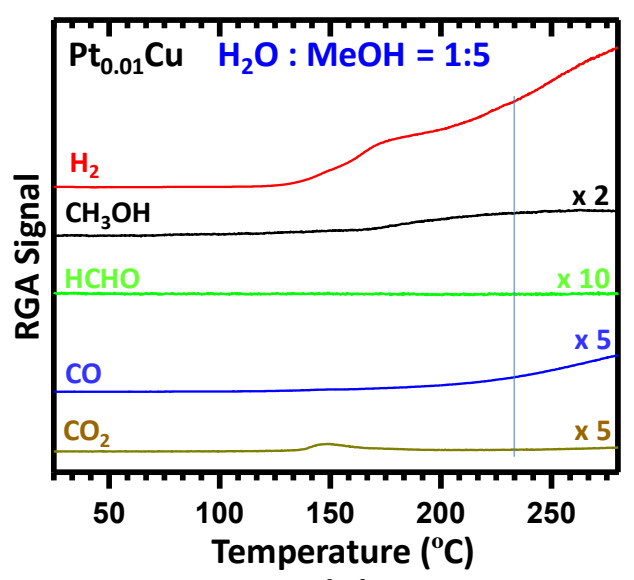

(A)

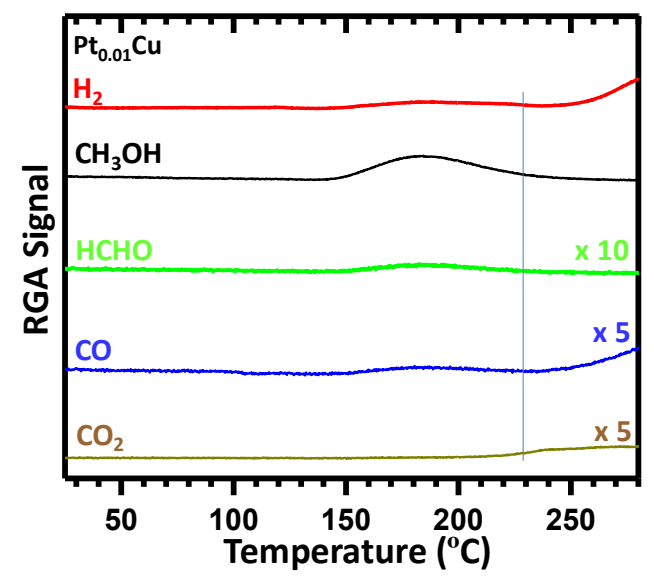

(B)

Fig. 9 TPSR of methanol on the silica supported $\mathrm{Pt}_{0.01} \mathrm{Cu}$ SAA nanoparticles with a water to methanol ratio of 1:5 (A) and with water to methanol ratio of 3:1 (B). Reaction conditions: (A) 100mg catalyst, 9\% methanol and $2 \%$ water balanced in $\mathrm{He}$, He flow rate $10 \mathrm{~mL} / \mathrm{min}$; (B) $100 \mathrm{mg}$ catalyst, $3 \%$ methanol and $9 \%$ water balanced in $\mathrm{He}$, He flow rate $10 \mathrm{~mL} / \mathrm{min}$.

Fig. 9 shows TPSR of methanol on the silica supported $\mathrm{Pt}_{0.01} \mathrm{Cu}$ SAA nanoparticles with a water to methanol ratio of 1:5 (A) and with water to methanol ratio of 3:1 (B). For the case with a water to methanol ratio of 1:5, there is no detectable formation of formaldehyde; while in the case with water to methanol ratio of $3: 1$, the yield of formaldehyde at $230{ }^{\circ} \mathrm{C}$ is only $1.2 \%$, which is much less than the $7 \%$ yield at 1:1 water to methanol ratio, Fig. 6B. As shown in Table 2, the yield of formaldehyde at $230{ }^{\circ} \mathrm{C}$ is also close to $7 \%$ at $7: 1$ water to methanol ratio. In these 
experiments, several measurements were taken, and the average yield of formaldehyde was used in Table 2. Thus, the best formaldehyde yield for water-catalyzed methanol dehydrogenation over supported $\mathrm{Pt}_{0.01} \mathrm{Cu}$ SAA nanoparticles is achieved at water to methanol ratio of $1: 1$, selected for further studies because it minimizes the amount of water for a practical application.

To further investigate the methanol dehydrogenation reaction, we performed TPD/R studies on model surfaces in UHV. Fig. 10 shows the TPD/R traces resulting from the adsorption of methanol-D $\left(\mathrm{CH}_{3} \mathrm{OD}\right)$ onto $\mathrm{Cu}(111)$. In agreement with previously reported desorption of methanol from $\mathrm{Cu}(111)$ [22, 40], we observe intact methanol-D (m/z 33) desorbing from $\mathrm{Cu}(111)$ terraces at $160 \mathrm{~K}$ and from $\mathrm{Cu}$ step edges at $200 \mathrm{~K}$. Small amounts of reactively formed formaldehyde $(\mathrm{m} / \mathrm{z} 30)$ desorbs from $\mathrm{Cu}(111)$ surface at $370 \mathrm{~K}$. Small amounts of reactively formed formaldehyde $(\mathrm{m} / \mathrm{z} 30)$ desorbs from $\mathrm{Cu}(111)$ surface at $370 \mathrm{~K}$. The fragmentation pattern of both methanol and formaldehyde includes $\mathrm{m} / \mathrm{z} 30$, however, at $370 \mathrm{~K}$, we observe desorption of $\mathrm{m} / \mathrm{z} 30$ independent of $\mathrm{m} / \mathrm{z} 33$ (methanol-D). Thus we conclude that reactively formed formaldehyde desorbs at higher temperatures. Additionally, water (m/z 18) from the chamber background is also observed desorbing from the surface at $150 \mathrm{~K}$, though the surface coverage of water is small at $0.2: 1$ water:methanol ratio. Water is known to co-catalyze the dehydrogenation of methanol on $\mathrm{Cu}$ in vacuum and will be discussed later [13].

Interestingly, when methanol is adsorbed on a roughened $\mathrm{Cu}(111)$ surface (Fig. 10A), the amount of reactively formed formaldehyde desorbing at $370 \mathrm{~K}$ increases. An increase in desorption of methanol-D at $200 \mathrm{~K}$ indicates that there is an increase in step sites on the roughened copper surface. Using STM, we imaged both a typical $\mathrm{Cu}(111)$ (Fig. 10B) and a roughened $\mathrm{Cu}(111)$ surface (Fig. 10C). A typical $\mathrm{Cu}(111)$ exhibits monoatomic steps separated by large terraces $(30-100 \mathrm{~nm})$. A roughened surface prepared through $\mathrm{Ar}^{+}$sputtering without annealing, yields a highly stepped surface. Using CO titration, we estimate the concentration of step sites on the roughened $\mathrm{Cu}(111)$ surface is $5 \mathrm{x}$ that of a typical $\mathrm{Cu}(111)$ surface. From this 
experiment we conclude that the higher density of $\mathrm{Cu}$ step sites increases the conversion of methanol to formaldehyde.

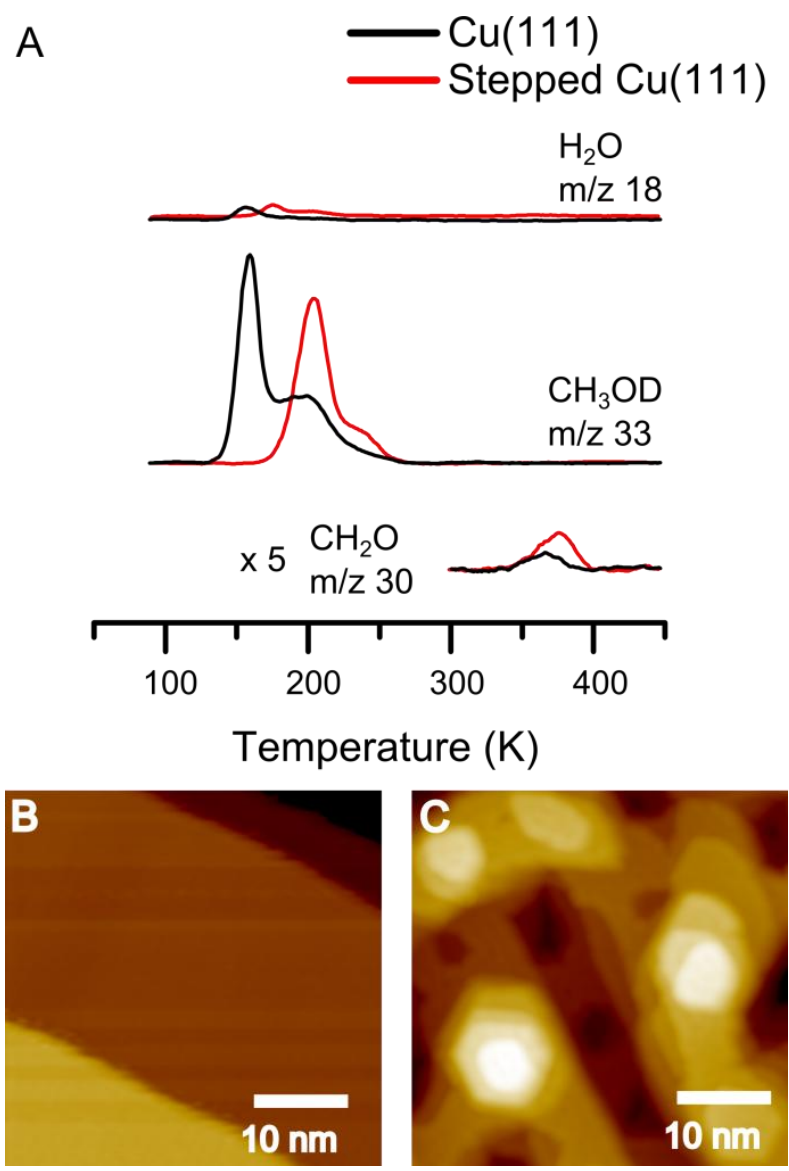

Fig. 10 (A) TPD/R traces for the adsorption of methanol on $\mathrm{Cu}(111)$ and a highly roughened $\mathrm{Cu}(111)$ surface. Methanol-D (0.6 monolayer $(\mathrm{ML})$ ) was adsorbed onto the surfaces (water:methanol = 0.2:1) Desorption traces for reactants water $(\mathrm{m} / \mathrm{z} 18)$ and methanol $(\mathrm{m} / \mathrm{z} \mathrm{33)}$ and the product formaldehyde $(\mathrm{m} / \mathrm{z}$ 30) are shown. STM images of a (B) typical $\mathrm{Cu}(111)$ surface and (C) roughened $\mathrm{Cu}(111)$ surface.

To investigate if $\mathrm{Pt}$ atoms can enhance the reactivity of $\mathrm{Cu}(111)$, we prepared $\mathrm{PtCu}(111)$ SAAs and probed the methanol dehydrogenation reaction (Fig. 11). We have previously characterized $\mathrm{PtCu}(111)$ SAAs and showed that the Pt atoms exist as isolated species dispersed in the $\mathrm{Cu}$ terraces at low Pt coverages $[41,42]$. In Fig. 11B, the Pt atoms appear in STM images as 
single protrusions in the $\mathrm{Cu}(111)$ terrace. TPD/R for the adsorption of methanol-D on $\mathrm{PtCu}(111)$ SAAs exhibits an increase in formaldehyde desorption (370 K) compared to the $\mathrm{Cu}(111)$ surface (Fig. 10A and 11A). Furthermore, the addition of Pt does not change the desorption temperature of methanol or formaldehyde; it only increases the production of formaldehyde. To further investigate the ability of $\mathrm{Pt}$ atoms to catalyze the reaction, we increased the concentration of $\mathrm{Pt}$ atoms in the $\mathrm{Cu}$ surface. Formaldehyde yield increases linearly as a function of Pt coverage in the single atom regime $(<0.05 \mathrm{ML} \mathrm{Pt})$, but begins to decrease beyond 0.05 ML Pt where clusters greater than one Pt atom exist in the surface. Additionally, PtCu SAAs exhibit high stability; the percent yield of formaldehyde remains constant at $9 \% \pm 1$ for 7 consecutive reaction cycles on the same PtCu SAA surface with 1:1 water to methanol ratio. 
A
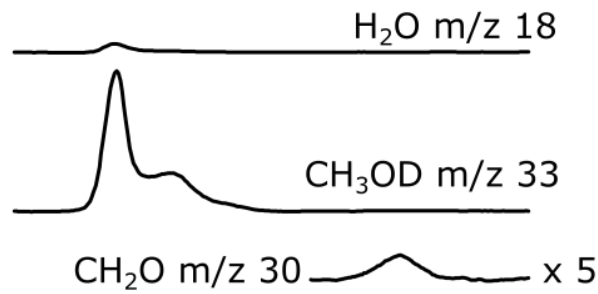

$\mathrm{H}_{2}$ m/z 2 rmm 10

$\mathrm{HD}$ 10

$\mathrm{D}_{2} \mathrm{~m} / \mathrm{z} 4 \underset{\sim}{\mathrm{m}} \times 10$
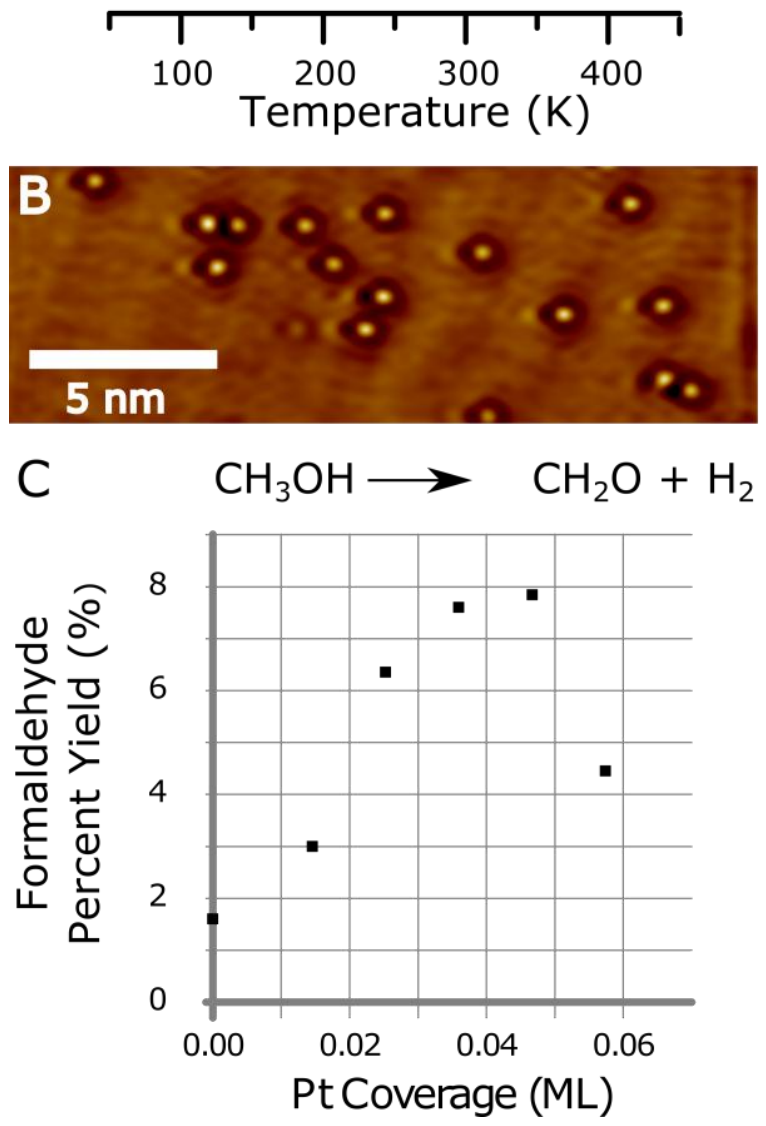

Fig. 11 (A) TPD/R traces of methanol on a PtCu SAA. 0.6 ML methanol-D was adsorbed on 0.01 ML $\mathrm{PtCu}(111)$ surface (water:methanol $=0.2: 1$ ). (B) STM image of $\mathrm{PtCu}(111)$ SAA surface where the bright features are $\mathrm{Pt}$ atoms substituted into the $\mathrm{Cu}(111)$ surface. (C) Formaldehyde percent yield versus $\mathrm{Pt}$ concentration for adsorption of 0.6 ML methanol adsorbed onto varying surface coverages of $\mathrm{Pt}$ (water:methanol $=0.2: 1$ ). 
Furthermore, we do not observe reactively formed $\mathrm{CO}$ desorbing from $\mathrm{PtCu}(111)$ SAA surfaces indicating that $\mathrm{PtCu}$ SAAs cannot fully decompose methanol resulting in $100 \%$ selectivity to formaldehyde on the Pt-Cu SAA surface. After increasing the coverage of Pt to 0.3 ML, a significant decrease in the amount of reactively formed formaldehyde and unreactive methanol is observed, reducing the selectivity to formaldehyde. This is due to an ensemble effect as at $0.3 \mathrm{ML} \mathrm{Pt}$ in $\mathrm{Cu}(111)$, our previous STM imaging data showed a heterogeneous atomic surface structure of $\mathrm{Pt}$ where linear clusters of $\mathrm{Pt}$ atoms were present on the surface $[35,42]$. We propose that these larger Pt ensembles are capable of decomposing formaldehyde or methanol since $\operatorname{Pt}(111)$ was observed to decompose methanol and formaldehyde [43].

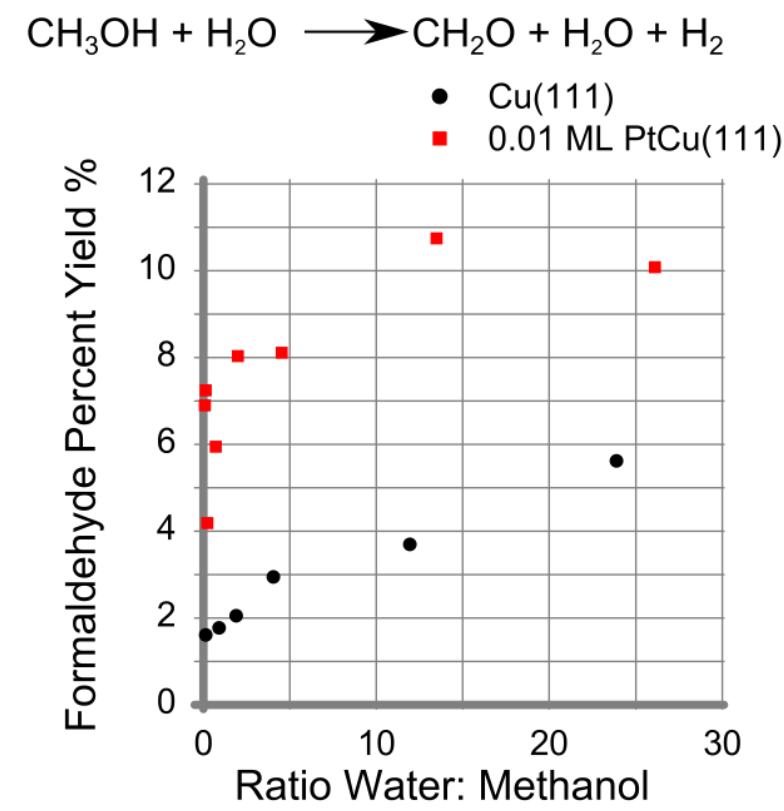

Fig. 12 Formaldehyde yield as a function of the ratio of water to methanol for $\mathrm{Cu}(111)$ and $\mathrm{PtCu}(111) \mathrm{SAA}$ surfaces. Methanol was adsorbed prior to water and the methanol surface coverage was 0.6 ML for each trial.

Table 3. Percent yield of formaldehyde for various coverages of water and methanol

\begin{tabular}{|c|c|c|c|}
\hline \multicolumn{2}{|c|}{$\mathrm{Cu}(111)$} & \multicolumn{2}{c|}{$0.01 \mathrm{ML} \mathrm{PtCu}(111)$} \\
\hline Water to Methanol ratio & Percent Yield & Water to Methanol ratio & Percent Yield \\
\hline
\end{tabular}




\begin{tabular}{|c|c|c|c|}
\hline 0.1 & $1.6 \%$ & 0.1 & $6.9 \%$ \\
\hline 0.9 & $1.8 \%$ & 0.2 & $7.2 \%$ \\
\hline 2.0 & $2.0 \%$ & 0.7 & $5.9 \%$ \\
\hline 4.1 & $2.9 \%$ & 2.0 & $8.0 \%$ \\
\hline 12.0 & $3.7 \%$ & 4.5 & $8.1 \%$ \\
\hline 23.9 & $5.6 \%$ & 13.5 & $10.7 \%$ \\
\hline & & 26.1 & $10.1 \%$ \\
\hline
\end{tabular}

To investigate the role of water in PtCu SAA catalysts, we co-adsorbed water and methanol onto a $\mathrm{PtCu}(111)$ SAA surface. Increasing the ratio of water:methanol led to an increase in the percent yield of formaldehyde on both $\mathrm{Cu}(111)$ and $\mathrm{PtCu}(111)$ SAA (Fig. 12) with PtCu SAAs being more reactive than $\mathrm{Cu}(111)$. At maximum formaldehyde conversion, $\mathrm{PtCu}$ SAAs are about twice as reactive as $\mathrm{Cu}(111)$. We previously reported that water co-catalyzes methanol dehydrogenation on $\mathrm{Cu}(111)$ surface [13]. Combining STM with TPD/R, we demonstrated that excess water is needed to convert methanol to formaldehyde on a $\mathrm{Cu}(111)$ surface. Since both water and methanol form hydrogen bonded clusters, the co-adsorption of methanol [44-46] and water $[47,48]$ results in methanol-water networks that assist in the dehydrogenation of methanol to methoxy.

Through our surface science studies, we investigated the active sites for the dehydrogenation of methanol. Although $\mathrm{Cu}(111)$ terraces are incapable of converting methanol to formaldehyde [13], we demonstrate the we can dramatically increase the reactivity of $\mathrm{Cu}$ through producing additional active sites and utilizing the co-catalyst water. First, increasing the step density on a $\mathrm{Cu}(111)$ surface doubles the conversion of methanol to formaldehyde in agreement with previous studies that demonstrate the formation of methoxy on $\mathrm{Cu}$ steps [13, 49]. Furthermore, addition of 0.01 ML isolated Pt atoms increases conversion to formaldehyde by 2 - 4 times depending on 
surface coverage of water (Table 3). Both $\mathrm{Cu}$ steps and PtCu SAA catalyze the reaction via a similar mechanism. With our TPD/R studies, we elucidate the mechanism for dehydrogenation of methanol on $\mathrm{PtCu}$ SAA surfaces. In order to identify desorption peaks for $\mathrm{O}-\mathrm{H}$ versus $\mathrm{C}-\mathrm{H}$ activation, we adsorbed methanol-D $\left(\mathrm{CH}_{3} \mathrm{OD}\right)$ (Fig. 11A). Intuitively, one would expect at low temperatures to observe the exclusive desorption of $\mathrm{m} / \mathrm{z} 4\left(\mathrm{D}_{2}\right)$ from the initial O-D bond scission, however, we observe desorption of m/z $2\left(\mathrm{H}_{2}\right)$ and $3(\mathrm{HD})$ at $250 \mathrm{~K}$ preceded by $\mathrm{m} / \mathrm{z} 19$ (HDO) at $160 \mathrm{~K}$. Since at $<100 \mathrm{~K}$ methanol is initially dehydrogenated to methoxy on $\mathrm{Cu}$ steps, the D adatoms isotopically exchange with $\mathrm{H}_{2} \mathrm{O}$ as previously reported by Mullins and co-workers on $\mathrm{Au}$ (111) $[23,24]$ or isotopic exchange occurs between $\mathrm{H}_{2} \mathrm{O}$ and $\mathrm{CH}_{3} \mathrm{OD}$, because excess water cocatalyzes the reaction on $\mathrm{Cu}$ surfaces. Due to the competition between methoxy formation and methanol desorption, we hypothesize that isolated Pt atoms increase the formation of methoxy on the surface. The methoxy is then converted to formaldehyde at higher temperatures. The high temperature desorption of $\mathrm{H}_{2}(\mathrm{~m} / \mathrm{z} 2)$ that coincides with formaldehyde desorption, supports $\mathrm{C}-\mathrm{H}$ activation as the rate limiting step to the formation of formaldehyde. This rate limiting step agrees with a previous report that $\mathrm{C}-\mathrm{H}$ bond scission occurs at $430 \mathrm{~K}$ on $\mathrm{Cu}(111)$ [50]. Furthermore, the overall process is reaction rate limited since formaldehyde desorption occurs from $\mathrm{Cu}$ surfaces < $200 \mathrm{~K}[15,51,52]$.

As discussed above, the water-catalyzed methanol dehydrogenation to formaldehyde on $\mathrm{Cu}$ surfaces was clearly observed both under realistic reaction conditions (Fig. 6) and UHV conditions (Fig. 10). Although water-catalyzed dehydrogenation of methanol has been observed on the $\mathrm{Cu}(111)$ surface under UHV conditions [12], it is the first time that this reaction has been observed under realistic reaction conditions. The promotion effect of water can be explained by the co-operative interactions of water and methanol facilitating the dehydrogenation of methanol to methoxy, thereby, increasing the formation of methoxy species. Methoxy can further dehydrogenate to formaldehyde by the activation of $\mathrm{C}-\mathrm{H}$ bond. Additionally, as observed in Fig. 
6, the stabilized methoxy can also undergo recombination with $\mathrm{H}$ atoms to desorb as methanol at higher temperature, which is kinetically more favorable in the absence of water. In the presence of water, however, stabilization of $\mathrm{H}$ atoms by water clusters increases the reaction barrier of recombination of methoxy and $\mathrm{H}$ therefore allows the dehydrogenation of methoxy to formaldehyde via the $\mathrm{C}-\mathrm{H}$ bond activation. Furthermore, we demonstrate that the catalytic activity of $\mathrm{Cu}$ surface originates from under-coordinated $\mathrm{Cu}$ atoms. Although the $\mathrm{Cu}(111)$ surface is active in the presence of water, the reactivity of $\mathrm{Cu}$ surface can be dramatically increased by increasing the step density of the $\mathrm{Cu}(111)$ surface.

Adding individual, isolated $\mathrm{Pt}$ atoms to $\mathrm{Cu}$ surface also significantly promotes the reactivity of $\mathrm{Cu}$ in water-catalyzed methanol dehydrogenation. In TPSR measurements in the flow reactor, the yield of formaldehyde on silica-supported $\mathrm{Pt}_{0.01} \mathrm{Cu}$ SAA nanoparticles is 7 times larger than on supported $\mathrm{Cu}$ nanoparticles (Fig. 6). In UHV conditions, depending on the concentration of water, the conversion of formaldehyde is $2-6$ times higher than on $\mathrm{Cu}(111)$ at comparable water concentrations (Fig. 12). Therefore, our data under both realistic reaction conditions and UHV supports the dramatic increase of formation of formaldehyde by addition of single $\mathrm{Pt}$ atoms in $\mathrm{Cu}$. We attribute this promotional effect to an increase in methoxy formation on PtCu SAAs. As we previously demonstrated, isolated $\mathrm{Pt}$ atoms reduce the desorption temperature for $\mathrm{H}_{2}[35,42]$, thereby facilitating the dehydrogenation of methanol to methoxy and increasing the surface coverage of methoxy, as well as allowing more conversion of methoxy to formaldehyde.

In a previous publication, we demonstrated that single $\mathrm{Pd}$ atoms in the $\mathrm{Cu}$ surface promote the water catalyzed methanol dehydrogenation [13]. In the current study, we found that the promotional effect of $\mathrm{Pt}$ is much more pronounced than Pd. Under UHV conditions, at low water to methanol ratio $(<1)$ the formaldehyde yield on $\mathrm{dCu}(111)$ is almost the same as on $\mathrm{Cu}(111)$ [13]; while the yield on $\mathrm{PtCu}(111)$ is 2 - 4 times larger than on $\mathrm{Cu}(111)$ at the same water to methanol ratio. TPSR measurements in Table 2 also show that under reaction conditions the formaldehyde 
yield on $\mathrm{Pd}_{0.01} \mathrm{Cu}$ SAAs is approximately $0.8 \%$ at $1: 1$ water to methanol ratio which is much lower than on $\mathrm{Pt}_{0.01} \mathrm{Cu}$ SAAs. We also performed tests with other Pd concentrations $\left(\mathrm{Pd}_{0.003} \mathrm{Cu}\right.$ and $\mathrm{Pd}_{0.05} \mathrm{Cu}$ ) and observed that the yield of formaldehyde from these samples was similar to $\mathrm{Cu}$. We propose that the increased reactivity for PtCu SAA can be rationalized based on BrønstedEvans-Polyani (BEP) relationship in terms of the adsorption strength of descriptor molecules affecting the reactivity [53-56]. For SAAs, PtCu SAAs bind key descriptor molecules stronger than PdCu SAAs and via the BEP would be expected to exhibit lower activation energies. We observed $\mathrm{CO}$ desorbing at a higher temperature from $\mathrm{PtCu}(111)$ SAAs (350 K) [35], than $\mathrm{PdCu}(111)$ SAAs (270 K) [55], despite similar desorption temperatures observed for $\mathrm{Pd}(111)$ and Pt(111) surfaces (450 K) [57, 58]. Additionally, Fu et al. predict that PtCu SAAs exhibit stronger binding of $\mathrm{H}$ atoms and a lower barrier for $\mathrm{H}_{2}$ activation consistent with the BEP relationship [59]. Due to the stronger binding of these molecules to PtCu SAAs, we propose that isolated Pt atoms are more reactive than $\mathrm{Pd}$ atoms, thereby enhancing the methanol activation to methoxy.

Furthermore, on $\mathrm{PtCu}(111)$ SAAs, a high conversion of methanol to formaldehyde is observed at rather low water to methanol ratios $(<1)$; while under reaction conditions at 1 bar, a slightly different trend is observed with the maximum formaldehyde yield at 1:1 water to methanol ratio (Table 2). Moreover at intermediate water to methanol ratio (3:1), the yield of formaldehyde decreases followed by an increase again at 7:1 water to methanol ratio. Obviously the relationship between formaldehyde yield and water:methanol ratio on $\mathrm{PtCu}$ SAAs is much more complicated than on $\mathrm{Cu}$ and it is hard to quantify the surface coverage of different species under catalytic operating conditions compared to the UHV TPR setup. The drop in formaldehyde yields at intermediate water coverages may be due to the interactions between water and methanol. As reported for $\mathrm{Au}(111)$, the cluster size and structure of water strongly influences the bonding of $\mathrm{H}$ atoms $[23,24]$. With increasing water coverage, the competitive adsorption of water and methanol may decrease the amount of methoxy formed on the surface, and therefore 
decrease the formaldehyde yields. On the other hand, the bonding of hydrogen atoms with water clusters is strongly influenced by water cluster size and structure [23], which is determined by water coverage [48]. Therefore the stabilizing effect of $\mathrm{H}$ atoms by water molecules could be significantly influenced by water coverage on the PtCu SAA surfaces, resulting in the observed variation of formaldehyde yields.

\section{Conclusions}

In this work we demonstrate that $\mathrm{PtCu}$ single atom alloys are active for the non oxidative dehydrogenation of methanol to formaldehyde and hydrogen in the presence of water. Although $\mathrm{Cu}$ itself is also active, addition of single $\mathrm{Pt}$ atoms in the $\mathrm{Cu}$ surface significantly improves the reactivity where the yield of formaldehyde is strongly dependent on the water to methanol ratio. The promotional effect of water is attributed to the stabilization of $\mathrm{H}$ atoms by water clusters that facilitate the dehydrogenation of methanol to methoxy, which can be further dehydrogenated to formaldehyde. Furthermore, PtCu SAAs exhibit both high selectivity and stability in the watercatalyzed methanol dehydrogenation. The selectivities to formaldehyde on PtCu SAA nanoparticle catalysts and on $\mathrm{PtCu}(111)$ SAA model catalysts are both nearly $100 \%$. PtCu SAA catalysts also exhibit very good stability in the flow reactor tests and under UHV conditions. The findings of this work are a new manifestation of the utility of combining UHV surface science and high-pressure reactor experiments in exploring reaction mechanisms and guiding realistic catalyst designs.

\section{Acknowledgements}

We thank the Department of Energy, DOE EFRC/IMASC grant\# DE-SC0012573 for the financial support of this work. Partial support of J.L. by DOE/BES grant DE-FG02-05ER15730 is 
also gratefully acknowledged. J. S. thanks Drs. Sungsik Lee and Benjamin Reinhart from Argonne National Lab for their assistance with the in-situ XAS experiments. The XAS research used resources of the Advanced Photon Source, a U.S. Department of Energy (DOE) Office of Science, User Facility operated for the DOE Office of Science by Argonne National Laboratory under Contract No. DE-AC02-06CH11357. Aberration-corrected electron microscopy research at

Oak Ridge National Laboratory was sponsored by the U. S. Department of Energy, Office of Energy Efficiency and Renewable Energy, Vehicle Technologies Office, Propulsion Materials Program.

\section{References}

[1] G. Reuss, W. Disteldorf, O. Grundler, A. Hilt, in: I.F. Ullmann, W. Gerhartz, Y.S. Yamamoto, F.T. Campbell, R. Pfefferkorn, J.F. Rounsaville (Eds.) Ullmann's Encyclopedia of Industrial Chemistry, VCH, Deerfield Beach, FL, USA, 1985, pp. p. 619.

[2] Formaldehyde: 2015 World Market Outlook and Forecast up to 2019, Merchant Research \& Consulting, Ltd, United Kingdom 2015.

[3] W. Dai, L. Ren, in: G. Ertl, H. Knözinger, J. Weitkamp (Eds.) Handbook of Heterogeneous Catalysis, Wiley-VCH, Weinheim, 1997, pp. p. 3256.

[4] N.Y. Usachev, I.M. Krukovskii, S.A. Kanaev, Petrol Chem+, 44 (2004) 379-394.

[5] S. Ruf, A. May, G. Emig, Appl Catal a-Gen, 213 (2001) 203-215.

[6] T. Yamamoto, A. Shimoda, T. Okuhara, M. Misono, Chem Lett, (1988) 273-276.

[7] K. Takagi, Y. Morikawa, T. Ikawa, Chem Lett, (1985) 527-530.

[8] L.P. Ren, W.L. Dai, X.L. Yang, Y. Cao, H.X. Li, K.N. Fan, Appl Catal a-Gen, 273 (2004) 8388.

[9] L.P. Ren, W.L. Dai, Y. Cao, F.X. Li, K.N. Fan, Chem Commun, (2003) 3030-3031.

[10] K. Hashimoto, N. Toukai, J Mol Catal a-Chem, 145 (1999) 273-280.

[11] M. Sagou, T. Deguchi, S. Nakamura, in: T. Inui (Ed.) Studies in Surface Science and Catalysis, Elsevier, Amsterdam, 1988, pp. p. 139.

[12] H.J. Li, A.C. Lausche, A.A. Peterson, H.A. Hansen, F. Studt, T. Bligaard, Surf Sci, 641 (2015) 105-111.

[13] M.B. Boucher, M.D. Marcinkowski, M.L. Liriano, C.J. Murphy, E.A. Lewis, A.D. Jewell, M.F.G. Mattera, G. Kyriakou, M. Flytzani-Stephanopoulos, E.C.H. Sykes, Acs Nano, 7 (2013) 6181-6187.

[14] M. Bowker, R.J. Madix, Surf Sci, 95 (1980) 190-206. 
[15] I.E. Wachs, R.J. Madix, J Catal, 53 (1978) 208-227.

[16] M. Bowker, Top Catal, 3 (1996) 461-468.

[17] J.E. Parmeter, X.D. Jiang, D.W. Goodman, Surf Sci, 240 (1990) 85-100.

[18] T.E. Felter, W.H. Weinberg, G.Y. Lastushkina, P.A. Zhdan, G.K. Boreskov, J. Hrbek, Appl Surf Sc, 16 (1983) 351-364.

[19] K. Fukui, K. Motoda, Y. Iwasawa, J Phys Chem B, 102 (1998) 8825-8833.

[20] R.B. Barros, A.R. Garcia, L.M. Ilharco, J Phys Chem B, 108 (2004) 4831-4839.

[21] J. Gong, D.W. Flaherty, R.A. Ojifinni, J.M. White, C.B. Mullins, J Phys Chem C, 112 (2008) 5501-5509.

[22] A.K. Chen, R. Masel, Surf Sci, 343 (1995) 17-23.

[23] M. Pan, Z.D. Pozun, W.Y. Yu, G. Henkelman, C.B. Mullins, J Phys Chem Lett, 3 (2012) 1894-1899.

[24] A.J. Brush, M. Pan, C.B. Mullins, J Phys Chem C, 116 (2012) 20982-20989.

[25] N. Takezawa, N. Iwasa, Catal Today, 36 (1997) 45-56.

[26] J.M. Thomas, Phys Chem Chem Phys, 16 (2014) 7647-7661.

[27] X.F. Yang, A.Q. Wang, B.T. Qiao, J. Li, J.Y. Liu, T. Zhang, Accounts Chem Res, 46 (2013) $1740-1748$.

[28] M. Flytzani-Stephanopoulos, B.C. Gates, Annu Rev Chem Biomol, 3 (2012) 545-574.

[29] Y.P. Zhai, D. Pierre, R. Si, W.L. Deng, P. Ferrin, A.U. Nilekar, G.W. Peng, J.A. Herron, D.C. Bell, H. Saltsburg, M. Mavrikakis, M. Flytzani-Stephanopoulos, Science, 329 (2010) 1633 1636.

[30] M. Yang, S. Li, Y. Wang, J.A. Herron, Y. Xu, L.F. Allard, S. Lee, J. Huang, M. Mavrikakis, M. Flytzani-Stephanopoulos, Science, 346 (2014) 1498-1501.

[31] G. Kyriakou, M.B. Boucher, A.D. Jewell, E.A. Lewis, T.J. Lawton, A.E. Baber, H.L. Tierney, M. Flytzani-Stephanopoulos, E.C.H. Sykes, Science, 335 (2012) 1209-1212.

[32] B.T. Qiao, A.Q. Wang, X.F. Yang, L.F. Allard, Z. Jiang, Y.T. Cui, J.Y. Liu, J. Li, T. Zhang, Nat Chem, 3 (2011) 634-641.

[33] F. Besenbacher, I. Chorkendorff, B.S. Clausen, B. Hammer, A.M. Molenbroek, J.K. Norskov, I. Stensgaard, Science, 279 (1998) 1913-1915.

[34] S.R. Zhang, J.J. Shan, Y. Zhu, A.I. Frenkel, A. Patlolla, W.X. Huang, S.J. Yoon, L. Wang, H. Yoshida, S. Takeda, F. Tao, J Am Chem Soc, 135 (2013) 8283-8293.

[35] F.R. Lucci, J. Liu, M.D. Marcinkowski, M. Yang, L.F. Allard, M. Flytzani-Stephanopoulos, E.C.H. Sykes, Nature Communications, 6 (2015) 8550.

[36] M.B. Boucher, B. Zugic, G. Cladaras, J. Kammert, M.D. Marcinkowski, T.J. Lawton, E.C.H.

Sykes, M. Flytzani-Stephanopoulos, Phys Chem Chem Phys, 15 (2013) 12187-12196.

[37] N.A. Dhas, C.P. Raj, A. Gedanken, Chem Mater, 10 (1998) 1446-1452.

[38] S. Jeong, K. Woo, D. Kim, S. Lim, J.S. Kim, H. Shin, Y.N. Xia, J. Moon, Adv Funct Mater, 18 (2008) 679-686.

[39] J.C. Brown, E. Gulari, Catal Commun, 5 (2004) 431-436.

[40] S.M. Johnston, A. Mulligan, V. Dhanak, M. Kadodwala, Surf Sci, 530 (2003) 111-119.

[41] F.R. Lucci, T.J. Lawton, A. Pronschinske, E.C.H. Sykes, The Journal of Physical Chemistry C, 118 (2014) 3015-3022.

[42] F.R. Lucci, M.D. Marcinkowski, T.J. Lawton, E.C.H. Sykes, The Journal of Physical Chemistry C, (2015) 150828132640007.

[43] K.D. Gibson, L.H. Dubois, Surf Sci, 233 (1990) 59-64.

[44] T.J. Lawton, J. Carrasco, A.E. Baber, A. Michaelides, E.C. Sykes, Phys Chem Chem Phys, 14 (2012) 11846-11852.

[45] T.J. Lawton, J. Carrasco, A.E. Baber, A. Michaelides, E.C.H. Sykes, Physical Review Letters, 107 (2011).

[46] C.J. Murphy, J. Carrasco, T.J. Lawton, M.L. Liriano, A.E. Baber, E.A. Lewis, A. Michaelides, E.C. Sykes, J Chem Phys, 141 (2014) 014701. 
[47] M. Mehlhorn, J. Carrasco, A. Michaelides, K. Morgenstern, Physical Review Letters, 103 (2009) 026101.

[48] A. Michaelides, K. Morgenstern, Nat Mater, 6 (2007) 597-601.

[49] J.N. Russel, S.M. Gates, J.T. Yates, Surf Sci, 163 (1985) 516-540.

[50] S. Pöllmann, A. Bayer, C. Ammon, H.P. Steinrück, Z. Phys. Chem., 218 (2004) 957-971.

[51] J.R.B. Gomes, J.A.N.F. Gomes, F. Illas, J Mol Catal a-Chem, 170 (2001) 187-193.

[52] T.R. Bryden, S.J. Garrett, J Phys Chem B, 1999 (1999) 10481-10488.

[53] J.K. Norskov, T. Bligaard, A. Logadottir, S. Bahn, L.B. Hansen, M. Bollinger, H. Bengaard, B. Hammer, Z. Sljivancanin, M. Mavrikakis, Y. Xu, S. Dahl, C.J.H. Jacobsen, J Catal, 209 (2002) 275-278.

[54] J. Greeley, M. Mavrikakis, Nature Materials, 3 (2004) 810-815.

[55] M.D. Marcinkowski, A.D. Jewell, M. Stamatakis, M.B. Boucher, E.A. Lewis, C.J. Murphy, G. Kyriakou, E.C.H. Sykes, Nature Materials, 12 (2013) 523-528.

[56] A. Logadottir, T.H. Rod, J.K. Norskov, B. Hammer, S. Dahl, C.J.H. Jacobsen, J Catal, 197 (2001) 229-231.

[57] X.C. Guo, J.T. Yates, Journal of Chemical Physics, 90 (1989) 6761-6766.

[58] D.M. Collins, W.E. Spicer, Surf Sci, 69 (1977) 85-113.

[59] Q. Fu, Y. Luo, J Phys Chem C, 117 (2013) 14618-14624. 